formed simultaneously. Actually the 'hyalodentine' layer is formed first. It is laid down after the manner of membrane bone, surrounded by osteoblasts. The term 'hyalodentine' should accordingly be dropped. The fibrillary plate is laid down against the bony layer, being formed probably from substances which have penetrated between the older osteoblasts.

Dept. of Zoology, Ferris Neave.

University of Manitoba, Winnipeg, Man. April 25.

1 Verh. anat. Ges. Jena, 41.

\section{Negrito Racial Strain in India}

THE remnants of the Negrito race in the aboriginal population of South India were first discovered by Dr. B. S. Guha and reported in NATURE ${ }^{1}$. In an extensive survey of the Perambiculam Hills within the Cochin State and the adjoining Anaimallais Hills of the Coimbatore district he found, in all, 16 individuals with spirally curved hair of whom one was a Pulayan, one a Mälser and the rest were Kadars. The hair of

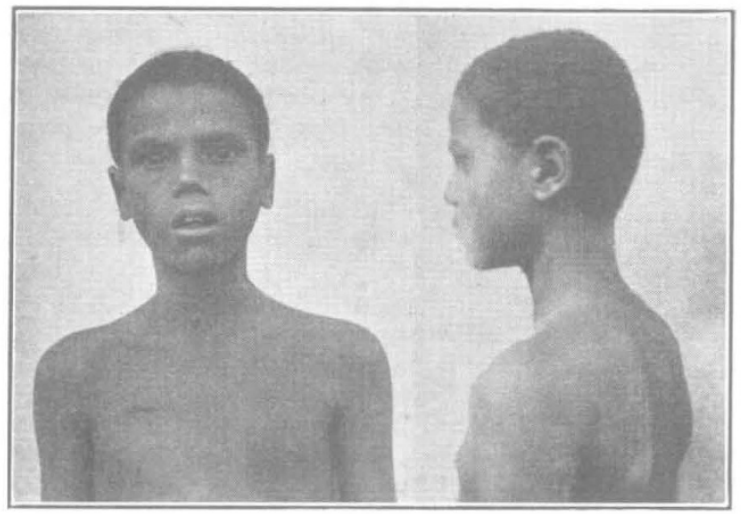

FIG. 1.

these people was of a frizzly type equivalent to No. $g$ of Martin's scheme ${ }^{2}$, with the exception of two individuals whose hair was of the woolly type and more like No. $h$ of the same scheme. In a recent survey of the Hill People of the Rajmahal Hills of Santal Parganas, I came across a boy of about fourteen years of age in a place called Lilkotidhāorā (Rajmahal subdivision) belonging to the Bāgdi group with short spirals of a distinctly woolly type (No. $h$ ) (Fig. 1). $\mathrm{He}$ was very short $(1,354 \mathrm{~mm}$.). The head was round and short, the maximum length and breadth being $166 \mathrm{~mm}$. and $142 \mathrm{~mm}$. respectively, and the proportions between the two was $85 \cdot 54$. The nose was flat and broad and the face was round and short. The lips, however, were moderate and no prognathism was noticed. The skin colour was black, corresponding to No. 33 of von Luschan scale.

The Negritos found by Dr. Guha were equally pigmented, but appeared to possess a more elongated head, only two showing a cephalic index of $77 \cdot 34$ and $79 \cdot 29$ respectively. Discussing the origin of these people, Dr. Guha has suggested ${ }^{3}$ that the basis of the Indian Negritos was probably brachycephalic, but large admixture with a primitive dolichocephalic Nisadic element had afterwards modified the head shape. The Rajmahal boy with woolly hair discovered by me would appear to lend support to this contention, and to indicate, as suggested by Dr. Guha, that the Negritos in India, like the Andamanese, were originally round-headed; and the change of the head shape has been due, as noticed to a smaller extent among the Semangs, to the large absorption of the blood of a primitive dolichocephalic race which is the dominant element among the aboriginal population of Southern and Central India at the present time.

Bose Research Institute, S. S. SARKAR.

93 Upper Circular Road, Calcutta.

1 NATURE, 121, 793 (May 19, 1928); and 123, 942 (June 22, 1929). "Lehrbuch", Second Ed., 1, 213

" "Census of India", 1, Pt. iii, p. li, 1935.

\section{Occurrence and Distribution of Chromosome Aberrations in Nature (Diptera)}

The problem of the frequency, types and distribution of chromosome aberrations in Nature has so far not been studied. Yet in analyses of spontaneous mutations, of the divergency of species and of the structure of population, this problem is of the greatest importance. Several separate cases on the occurrence and distribution of different aberrations in Nature have been described (Sturtevant, Blakeslee, Brink and others).

In the summer of $1935,1,666$ chromosome com. plexes from the salivary gland cells of the larvæ of D. melanogaster from five populations (Kutais, Gori, Batoum, Souchoum, Gelendzhik) were studied. Five different inversions were detected in the large autosomes. Rather high concentrations of inversions were observed in the populations (the percentages of heterozygotes were $5 \cdot 24 ; 1.02 ; 8.28 ; 0.0 ; 14.8$ ), owing to which individuals homozygous for inversions were found.

The most frequent chromosome aberration in $D$. melanogaster which contained an inversion in each of the limbs of the second chromosome (CIIL-CIIR) proved to be an allelomorph of the inversion CIILCyCIIR which was found by Ward in Michigan (1918). Genetic experiments have shown that the individuals possessing two of these inversions are viable and an analysis of the salivary gland chromosomes has shown that they are identical.

The chromosomes of $D$. funebris were studied in 1935-36 in populations taken during December and January in two localities of Moscow. 220 individuals were investigated. About 75 per cent of them con. tained inversions. Due to this high concentration, some of the individuals were homozygous for inversions and others were heterozygous for two or three of them.

A preliminary study of populations of $D$. obscura and other species of Drosophila has also shown the existence of inversions.

An investigation of 250 larvæ from three wild populations of Chironomidæ has shown 20,43 and 65 per cent of individuals heterozygous for inversions.

All 434 chromosomes bearing inversions have been found. In the species studied about 30 per cent of individuals were heterozygous for inversion.

The outstanding fact that all other types of chromosome aberrations except inversions are missing, proves that their concentration in the populations of the species is very low. This may be caused either by 